\title{
APRESENTAÇÃO - Vol. 16, N. 3
}

A partir da década de 1990 e início dos anos 2000, a produção de conhecimentos na área da Educação no Brasil absorveu e ampliou debates acerca dos direitos humanos e garantia de acesso e permanência de estudantes, considerados como "minoritários", nos bancos escolares. A organização e ampliação do movimento LGBTI+ (Lésbicas, Gays, Bissexuais, Travestis, Transexuais e demais estéticas de existência que rompem com os binarismos de gênero), o contato com textos feministas de Audre Lord, Joan Scott, Guacira Louro, Margareth Rago, Eve Sedwuick e Judith Butler, bem como as conquistas do movimento negro, que culminou na promulgação da Lei 10.639/2003 (ampliada para questões indígenas em 2008), são algumas das condições históricas que materializam a compreensão da Educação como um território de enfrentamentos. Enfrentamentos estes que visam garantir o direito do acesso e permanência de estudantes nos processos de escolarização. Que provocam os currículos a se reformularem para garantir representações positivas de grupos historicamente excluídos. Que provocam a expulsão compulsória da Educação Básica "disfarçada" de evasão. Que potencializam com que estudantes e pesquisadorxs que subvertem a lógica de normalidade do gênero, sexualidade, geração, cor/etnia, religião e territorialidade nomeiem e visualizem processos socioculturais de classificação, hierarquização e subjugação que tentam capturar corpos que ousam rebeldia. Que provocam as universidades a pautar questões de garantia de vida e recusa à necropolítica. Por meio de inquietações, em muito movimentadas pelo atual contexto político, estudantes, educadorxs e pesquisadorxs têm procurado articular sérias discussões a fim de fundamentar a formulação de políticas educacionais, bem como tornar cotidiana (por mais que diferentes estéticas de existência sempre compuseram as práticas escolares!) a compreensão da complexidade humana que compõe os espaços educativos e a práxis pedagógica na educação escolar. É nesta perspectiva que se insere o presente dossiê, cujo objetivo é (re)apresentar provocações teórico-conceituais sobre os processos de marcação social de diferenças e posicionamento social de vidas que, em muitos casos, não são consideradas como "humanas". 
Neste sentido, o ensaio que inaugura o dossiê, intitulado "Diversidade sexual, gênero e sexualidades: temas importantes à educação democrática", de Marcio Caetano, Carlos Henrique Lucas Lima e Amanda Motta Castro, defende, a partir de um trabalho realizado com docentes da Bahia e do Rio Grande do Sul, uma escola que promova o respeito às dissidências de gênero e sexualidade, elementos indissociáveis da sociedade democrática.

O artigo seguinte "Memórias de homossexualidades, escolarizações e homofobias", de Fernando Guimarães Oliveira da Silva e José Antonio de Souza, discute as memórias de indivíduos masculinos e homossexuais acerca das violências sofridas durante o período escolar.

Em "Fotonarrativas de práticas pedagógicas: uma análise sobre as percepções de gênero na educação infantil", Raquel Batista e Bárbara Cristina Moreira Sicardi Nakayama exibem os resultados de uma pesquisa que demonstrou que algumas professoras pretendem trabalhar com práticas que objetivem a equidade de gênero.

Na sequência, o artigo de Adriano Rogério Cardoso e Tânia Regina Zimmermann intitulado "Gênero e educação, interfaces com grafitos em uma ambiência escolar: possibilidades de pesquisa" debatem a necessidade de se visibilizar na de formação profissional e continuada de docentes as representações das sexualidades e de gênero presentes em grafitos produzidos por adolescentes.

Em "Reflexões de projeto extensionista: a trajetória negra contada e cantada por meio do samba", Tatiane Kelly Pinto de Carvalho e Maraísa Inês de Assis Martins exibem os resultados de um projeto que trabalhou a importância da cultura negra e a da diversidade na sociedade brasileira.

Encerrando o dossiê, temos o artigo "As relações étnico-raciais e os currículos dos cursos de licenciatura de uma universidade do Mato Grosso do Sul", de Felipe de Lima Silva, Andressa Florcena Gama da Costa e Thalita Pereira da Silva que analisou como as licenciaturas de todos os campus de uma instituição de ensino superior trataram das relações étnico-raciais em seus currículos atendendo à lei no 10639/03.

Em seguida, são apresentados os artigos que compõem o fluxo contínuo. Matheus Fernandes de Castro, Lanna Gagliardi Tinoco, Eduardo Moura Souza e Jéssica Fernanda de Paula discutem no trabalho "Ambiente virtual: um estudo exploratório com estudantes universitários" o entendimento dos discentes de uma universidade pública do interior do 
estado de São Paulo a respeito do Ambiente Virtual assim como seus impactos na cotidianidade.

O artigo intitulado "Opelina Rollemberg: educadora protagonista da enfermagem sergipana", de Kelly Rocha, Sandro Rogério Almeida Matos Júnior, Angela Barros, Pacita Aperibense e Simone Amorim, apresenta aspectos do processo formativo da enfermagem em Sergipe destacando a importância da educadora na promoção da saúde no contexto de referido estado.

Gisele Silva Araújo e Manoel Osmar Seabra Júnior propõem no artigo "Educação e autismo: modelo metodológico para avaliação e a adaptação de games", um modelo metodológico para a avaliação e a adaptação de games à estudantes com autismo.

No artigo seguinte intitulado "A polêmica em torno da literatura indianista no Instituto Histórico e Geográfico Brasileiro 1838-1860", Thiago Granja Belieiro analisa o papel do IHGB nos debates concernentes a viabilidade de se ter o indígena em destaque na literatura.

No texto "Escola e conhecimento: em defesa dos clássicos e da crítica", Rafael Rossi e Aline Santana Rossi problematizam a relação entre conhecimento e educação escolar, respaldando-se na ontologia lukacsiana e na pedagogia histórico-crítica.

No artigo intitulado "A observação na educação infantil como forma de respeito às crianças", Viviane Barrozo Manfré e Cinthia Magda Fernandes Ariosi refletem sobre o conceito de observação que aplicado à prática educativa na educação infantil, possibilita o estabelecimento de aprendizagens significativas.

O último artigo que compõe o fluxo contínuo, "Formação docente e a língua brasileira de sinais: perspectivas atuais", de Lais Agnes da Silva e Renata Portela Rinaldi, expõe uma pesquisa sobre as publicações decorrentes das reuniões nacionais da Associação Nacional de Pós-Graduação e Pesquisa em Educação, do Congresso Brasileiro de Educação Especial e as presentes no Portal de Periódicos da CAPES, apontando o número reduzido de produções científicas sobre os estudos sobre a prática da Língua Brasileira de Sinais (Libras) nos cursos de formação inicial de docentes.

Por fim, a partir de um pensamento nômade, que não encerra debates acadêmicos em uma única perspectiva, pensamos contribuir para a visibilidade do confronto de ideias, pluralidade de pensamento e defesa dos reais objetivos da Educação sinalizados em uma 
Constituição que se vê, constantemente, esquecida. Divergências são bem-vindas, todavia, que a polarização do debate não assassine alguns "imperativos categóricos" que garantam a existência, dignidade e enfrentamento aos regimes normativos que regulam vidas para atenderem a ideais, nem sempre, construídos em colaboração coletiva. Boa leitura!

Prof. Dr. Jorge Luís Mazzeo Mariano Prof. Dr. Vagner Matias do Prado (Organizadores) 